\section{Seasonal Fluctuations and Distribution of Nitrite in a Tropical West African Estuary}

VERY little is known about the distribution and seasonal fluctuations of inorganic nitrogen in West African estuaries. I have given ${ }^{1}$ some preliminary figures based on a series of spot analyses and found that in the Sierra Leone River estuary there are both horizontal and vertical gradients in the concentrations of nitrite, nitrate and ammonia, with the higher values in the upstream direction and with increasing depth. The concentration of nitrite was found to vary from 8 to $4 \mathrm{mgm}$. nitrogen $/ \mathrm{m}^{3}$, nitrate from 141 to $74 \mathrm{mgm}$. nitrogen $/ \mathrm{m}^{3}$ and ammonia from 22 to $10 \mathrm{mgm}$. nitrogen $/ \mathrm{m}^{3}$ - samples taken over a period of only 3 months were, however, examined.

The present investigation was carried out in the Sierra Leone River estuary over a period of one year, using the Griess-Ilosva method for determining nitrite nitrogen as modified by $\mathrm{Orr}^{2}$ and Wattenberg ${ }^{3}$. Only the nitrite content of the estuarine water was determined in this investigation, but it is hoped that later it will be possible to study the seasonal changes and distribution of both nitrate and ammonia in order to throw some light on the nitrogen cycle. It is probable that fluctuations in nitrogen and phos. phorus may, with other factors such as the amount of effective light, be responsible for the phytoplankton 'bloom' which has been shown by 'Bainbridge' to occur during the period January-July. 'This 'bloom' was also found by $\mathrm{me}^{5}$ and by Bainbridge ${ }^{6}$ to coincide with an increase in the fat content of the local shad, Ethmalosa dorsalis (C. \& V.), which is caught in the estuary in fairly large numbers.

Fig. 1 shows the average concentration of nitrite in the surface water for the central region of the estuary during the year 1960. There is a marked seasonal fluctuation, with the higher values occurring in the wet season (June-November). The maximum concentration of nitrite and minimum salinity do not, however, fall within the same month ; this suggests that nitrite accumulates in the drainage area during the dry season (October-May) and is removed at the beginning of the wet season. The increment to the nitrite content of the estuary through the direct action

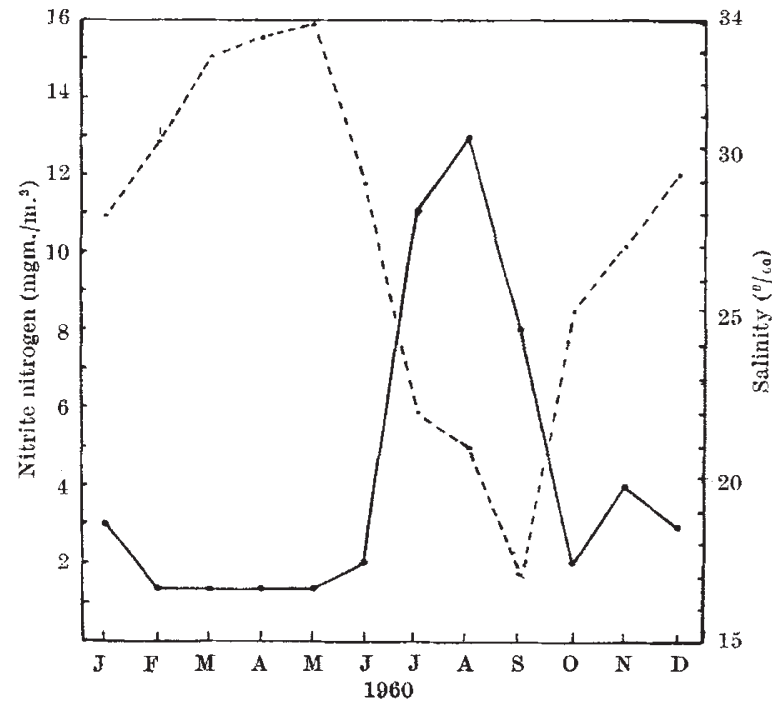

Fig. 1. Seasonal tuctuation of nitrite in the surface water for the central region of the Sierra Leone River Estuary. Yitrite, - of rainfall was not measured ; but it may be appreciable since large quantities of dust of Sahara origin are removed from the atmosphere by the convectional rains in June and early July.

Nitrite values for the feeder streams are also high in the wet season-a fact which suggests that the high values for nitrite in the estuarine water are not entirely due to increased turbulence as a result of the larger volume of fresh-water entering the upper reaches at this time of the year. $\mathrm{I}^{7}$, and also Longhurst ${ }^{8}$, have shown that the bottom deposits in the central region of the estuary are largely composed of muds with a relatively high organic content, whereas in the upper reaches and mouth the deposits consist of sand or gravel. From this distribution of the organic material in the estuary, it would be expected that vertical mixing should result in higher nitrite values in the central reaches rather than at the two ends, since the suspended material in the central reaches would contain a higher proportion of organic matter brought up from the bottom. That this is actually the case may be seen from Table 1, although the amount of nitrite contributed by the suspended detritus is clearly less than that from the feeder streams.

Table 1. Concentration of Nitrite IN the Estuary Water

\begin{tabular}{|c|c|c|}
\hline $\begin{array}{c}\text { Range of salinity } \\
\text { (gm. per 1,000 gm.) }\end{array}$ & $\begin{array}{c}\text { Average nitrite } \\
\text { nitrogen (mgm./m. }\end{array}$ & $\begin{array}{c}\text { No. of } \\
\text { observations }\end{array}$ \\
\hline $0-15$ & 8 & 15 \\
$16-20$ & 10 & 13 \\
$21-25$ & 10 & 26 \\
$26-30$ & 4 & 73 \\
$>30$ & 1 & 27 \\
\hline
\end{tabular}

Values for nitrite obtained during the flood and ebb at springs and neaps differed by no more than $1 \mathrm{mgm}$. nitrogen $/ \mathrm{m}^{3}$ during the dry season and $3 \mathrm{mgm}$. nitrogen $/ \mathrm{m} .{ }^{3}$ during the wet season. The horizontal gradient was most marked in the wet season; in July, the average value for nitrite at the mouth was $7 \mathrm{mgm}$. nitrogen $/ \mathrm{m}^{3}$ and 18 miles upstream $13 \mathrm{mgm}$. nitrogen $/ \mathrm{m} .^{3}$. During the greater part of the dry season, however, nitrite appears to be fairly evenly distributed in the surface water throughout the length of the estuary.

Fisheries Development and Research Unit, Freetown.

Watts, J. C. D, Bull. IFAN, 20, A, 3 (1958).

Orr, A. P., J. Mar. Biol. Assoc., 14 (1926).

${ }^{3}$ Wattenberg, H., Ann. d. Hydrogr., 59 (1931).

Bainbridge, V., Col. Off. Fish. Pub, 13 (H.M.S.O., 1960).

Watts, J. C. D., Bull. IFAN, 19, A, 2 (1957).

- Bainbridge, V., Nature, 179, 874 (1955).

? Watts, J. C. D., Bull. IF AN, 19, A, 3 (1957).

${ }^{8}$ Longhurst, A. R., Col. Off. Fish. Pub., 11 (H.M.S.O., 1958).

\section{Diurnal Rhythm in Cave Crayfish}

Numerous investigations have suggested persistent diurnal physiological rhythmicity to be the rule among organisms, inhabiting the natural day-night environment. However, the only report known to me of results of a study of an animal fully removed for innumerable generations from such daily changes in light and temperature, the case of the cave crayfish, Orconectes pellucidus (Tellkampf), clearly established that these possess no difference in activity between day-time and night-time when kept under controlled conditions in the laboratory ${ }^{1}$. 